\title{
Fracture toughness and crack growth of brackish ice using chevron-notched specimens
}

\author{
LARS STEHN \\ Department of Civil Engineering, Lulea University of Technology, S-971 87 Lulea, Sweden
}

\begin{abstract}
Field-test equipment called FIFT (a Field Instrument for Fracture toughness Tests on ice) was used in both field and laboratory fracture-toughness tests on brackish sea ice from the Gulf of Bothnia. An experimental calibration was performed and a compliance expression was then derived for the Short Rod Chevron Notched (SRCN) specimen. Using the SRCN configuration, for which the initial crack growth is shown to be stable, and measured load-point displacements, preliminary crack-growth velocities are found. The obtained estimated crack velocity is, on average, $\dot{a}_{\mathrm{e}}=20 \mathrm{~m} \mathrm{~s}^{-1}$, albeit with a large standard deviation. The results indicate that critical crack (crack-jumping) growth occurs. The apparent fracture toughness, $K_{\mathrm{Q}}$, was found to have a pronounced dependency on porosity in the form of brine volume. The results obtained are derived from a linearly elastic fracture mechanics (LEFM) theory. Consequently, the tests were designed to satisfy smallscale yielding requirements in terms of notch sensitivity and brittleness. The linearity of the load vs crack-opening displacement curves together with a size-effect study, showing that the specimen is notch-sensitive for grain-sizes ranging from 1.6 to nearly $100 \mathrm{~mm}$, indicate that LEFM could be applicable.
\end{abstract}

\section{INTRODUCTION}

Ice-structure interaction results in loads. Structures in cold regions must be designed to withstand forces that ice can exert. A number of investigations have studied the mechanisms of ice failure. Ice can fail by a continuum mode of failure or by a fracture mode of failure. Fracture appears to be the dominant failure mode in Nature and the presence and growth of cracks are of great importance to the final loading level, e.g. Fransson and others (1991). Thus, the study of fracture mechanics is important in iceengineering problems in order to obtain the necessary knowledge regarding the physics of fracture in laboratory-grown and naturally occurring ice. A survey of recent fracture-toughness tests on sea ice has been summarized by Stehn (1991); it is clearly evident that before fracture mechanics can be safely applied to iceengineering problems, further basic understanding of the mechanical behavior of sea ice is needed.

In the field, cracks are exposed to sublimation, free water and creep deformation in the vicinity of the crack tip that makes them heal and blunt. Parsons (1990) demonstrated that a crack in ice can remain atomically (mathematically) sharp and that cracks do not extend slowly through creep. Dempsey and others (1990) and DeFranco and others (1991) found that there is a necessary minimum notch-tip radius that must be attained if fracture-toughness tests on fresh-water ice and saline ice are to be interpreted in terms of linear elastic-fracture mechanics (LEFM). In the light of these findings, it is clear that in fracture-toughness testing it is essential to prepare a crack that is truly sharp". A sharp crack is a necessary but not sufficient condition for the applicability of LEFM which also relies on the energydissipation process in the body being near local to the crack tip in order not to affect the overall elastic response, the so-called case of small-scale yielding. For metals, small-scale yielding has been stated in ASTM E399 (1983) and requires a large crack length compared with the grain-size. However, for cracks comparable to the grain-size (as often can be the case for fracture testing on ice) the toughness obtained can only be regarded as a quasi-polycrystalline value which in no way fulfils the requirements for LEFM. Thus, the geometrical dimensions of the test specimen must be large enough to be notch-sensitive. In this context, the geometry is considered notch-sensitve if the net failure stress stays constant with increasing crack length (at least within a certain crack-length interval). Specimens having cracks outside this interval may experience a strength failure instead of an LEFM-type fracture failure and is referred to as notchinsensitive (Dempsey and others, 1992).

The specimen selected for this study is the Short Rod Chevron Notched (SRCN) specimen (see Fig. 1). The

* The considerable scatter for the fracture toughness found in the literature is not unexpected since different loading rates, temperatures, grain-sizes, crack orientations and loading geometries were used. In addition, the results are highly influenced by the methods, or lack of methods, to fabricate and sharpen the cracks. 


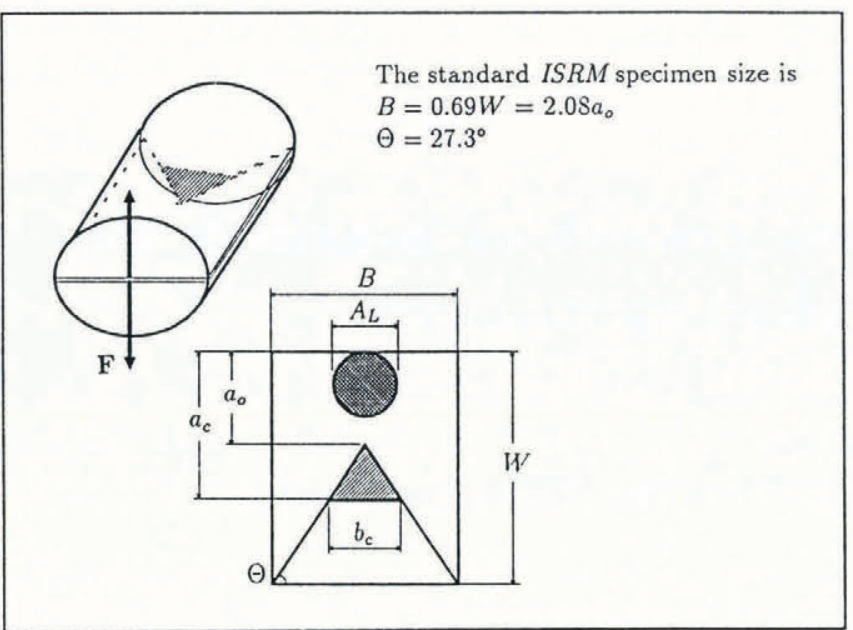

Fig. 1. The short-rod chevron-notched, $S R C N$, specimen geometry with standard configuration according to ISRM (1988).

apparent fracture toughness, $K_{\mathrm{Q}}{ }^{\dagger}$ for chevron-notched specimens in general, here the SRCN specimen, is determined from a quasistatically growing macro-crack. An initial crack of length $a_{0}$ initiates from the chevron tip upon loading. For materials such as aluminum (Shannon and Munz, 1984) and rock (Ouchterlony, 1989a), the crack advances in a stable manner under increasing load due to the special geometry of the chevron notch. This initial quasistable crack growth will produce a sharp macro-crack. Unstable crack growth occurs at the maximum load corresponding to a critical crack length, $a_{\mathrm{c}}$, which is a function of the specimen geometry alone ${ }^{\ddagger}$. Thus, the SRCN specimen appears to be well suited for obtaining near $K_{\mathrm{Ic}}$ values for rate-dependent materials, since no crack-tip sharpening method should, in theory, be needed.

To date, the emphasis has been on determining the fracture toughness corresponding to the initiation of a stationary macro-crack. For toughness tests, without the consideration of crack-growth stability, only single determination of $K_{\mathrm{Ic}}$ is possible. The stable crack-growth characteristic of sea ice and fresh-water ice is desirable for a number of reasons: it permits the crack-growth resistance, $R$, to be determined as a function of crack velocity, $\dot{a}$ and amount of crack growth, $\Delta a$; it permits the design of controlled experiments; it permits the toughening effect of the micro-structure on the crack growth to be determined and it permits the evaluation of the critical energy-release rate, $G_{\mathrm{Ic}}$. Crack stability and growth on ice have only lately received any attention (Parsons and others, 1988, 1989; DeFranco and Dempsey,

†Due to the lack of a fracture-toughness testing standard for ice, the notation $K_{\mathrm{Q}}$ should be used to denote an apparent fracture toughness (Dempsey, 1989). This type of notation has long been used in the fracture-toughness testing of rock, e.g. Ouchterlony (1982).

‡Only for materials with flat crack-growth resistance curves, $R$ curves, does the maximum load correspond to the critical crack length $a_{\mathrm{c}}$. For materials with rising $R$ curves, maximum load does not occur coincidently at $a_{\mathrm{c}}$.
1990, 1991). Controlled crack propagation may often be achieved simply by the choice of the appropriate specimen geometry. The SRCN specimen is known to promote quasistable crack growth which is also clear from energy-balance calculations. From this discussion, the SRCN concept is felt to be especially suitable for fracture studies on ice. Three main conclusions can be reached:

The LEFM approach is valid provided that three essential conditions are met: (A) the crack tip is sharp, (B) the crack length must be large in comparison with the grain-size, and (C) the specimen size must be sufficiently large in comparison with the crack-tip energy-dissipation zone for the stress and deformation fields surrounding the crack to be elastic.

Further basic understanding of the behavior of sea ice is needed. This knowledge is best gained from a combination of field measurements and laboratory studies.

The SRCN geometry offers several advantages: the cylindrical form is obtained from ordinary core drilling and the shaping of the desired form can easily be carried out in situ; it gives quasistatic crack growth in other brittle solids and has a favorable design for a minimum of released strain energy.

The present work includes: the development (with the above conclusions in mind) of a test system called FIFT (a Field Instrument for Fracture toughness Tests on ice) using the SRCN specimen geometry; the crack-growth stability and velocity; a minimum specimen-size criterion parallel to Dempsey (1991) in terms of notch sensitivity and brittleness; the influence of porosity on the apparent fracture toughness with respect to first-year granular and columnar (often warm and rafted) brackish sea ice from the Gulf of Bothnia.

\section{SRGN SPECIMEN GEOMETRY AND CALIBRATION}

The SRCN with basic notation is shown in Figure 1. In this study the specimen configuration suggested by the International Society for Rock Mechanics, (ISRM, 1988), will be used. With the specimen diameter, $B$, as the measure of the specimen size, four independent parameters describe the uncracked geometry. The mode I energy-release rate, $G_{\mathrm{I}}$ is given by

$$
G_{\mathrm{I}}=\frac{F^{2} \partial C}{2 b \partial a}
$$

where $C$ is the elastic compliance $\left(\delta_{\mathrm{F}} / F\right)$ and $\delta_{\mathrm{F}}$ the loadpoint displacement and $b$ the trapezoidal crack-front width which for a given dimensionless crack length, $\alpha=a / W$, is given by $b=B\left[\left(\alpha-\alpha_{0}\right) /\left(1-\alpha_{0}\right)\right]$. Accordingly, re-arrangement of Equation (1) in terms of the linear elastic stress-intensity factor, $K_{\mathrm{I}}^{2}=G E^{\prime}$, to obtain the shape function gives

$$
Y^{\prime \prime}=\left[\frac{1}{2} \frac{\partial C^{\prime}(\alpha)}{\partial \alpha} \frac{1-\alpha_{\mathrm{o}}}{\alpha-\alpha_{\mathrm{o}}}\right]^{1 / 2}=\frac{K_{\mathrm{I}} B \sqrt{W}}{F} .
$$

Here, $C^{\prime}$ is the dimensionless compliance, $C^{\prime}=C E^{\prime} B$, where $E^{\prime}$ is the effective elastic modules $=E$ for plane 
stress, $=E /\left(1-\nu^{2}\right)$ for plane strain. For a sufficiently brittle material the stress-intensity factor attains its critical value when the load reaches a maximum: $F_{\max }$ at $Y^{\prime \prime}=Y_{\min }^{\prime \prime}\left(W / B, \alpha_{\mathrm{c}}, \alpha_{0}\right)$ where $\alpha_{\mathrm{c}}$ is the dimensionless critical crack length.

$$
K_{\mathrm{Q}}=\frac{F_{\max }}{B \sqrt{W}} Y_{\min }^{\prime \prime}\left(W / B, \alpha_{\mathrm{c}}, \alpha_{0}\right) .
$$

To the author's knowledge, no analytical solution for the shape function is available. Various calibrations are therefore necessary for the derivation of $Y_{\min }^{\prime \prime}$. The most complete calibrations are to be found in Bubsey and others (1982) and Shannon and others (1982), and in Matsuki and others (1991). For the application to FIFT where a pressure is applied over a circular load area, the SRCN specimen was calibrated for a load-area loading (see Stehn, 1990). Three specimens were taken from a $200 \mathrm{~mm}$ diameter polypropylene cylinder. The sizes of the diameter $B$ and the length $W$ were varied to provide load-area to diameter ratios of $A_{\mathrm{L}} / B=0.27,0.54$ and 0.81 . The crack length was increased in steps so that $\Delta \alpha \approx 0.05$ for $\alpha_{0} \leq \alpha \leq 0.95$. To reduce errors, slope (compliance) measurements were taken as averages over two load cycles. A value was obtained during loading and unloading in each cycle.

It became clear that $Y_{\min }^{\prime \prime}$ and $\alpha_{\mathrm{c}}$ are rather insensitive to variations in $A_{\mathrm{L}} / B$. The maximum deviation in $Y_{\min }^{\prime \prime}$, compared to the ISRM standard, was found to be about $1.5 \%$, which is negligible compared with the uncertainties in the measured values. A change in the type of loading appears to alter the shape function in the manner described by Ingraeffa (1984) and Matsuki and others (1991).

The curve that best fitted the compliance-data plotted in Figure 2 was to be:

$$
C^{\prime}=\mathrm{e}^{\left(25.08-45.37 \alpha^{2}+29.94 \alpha^{3}\right)} .
$$

Thus, $Y^{\prime \prime}$ for SRCN using FIFT may be calculated according to Equation (2) as

$$
Y^{\prime \prime}=\left[C^{\prime}\left(12.54-45.37 \alpha+44.91 \alpha^{2}\right)\left(1-\alpha_{0}\right) /\left(\alpha-\alpha_{0}\right)\right]^{\frac{1}{2}} .
$$

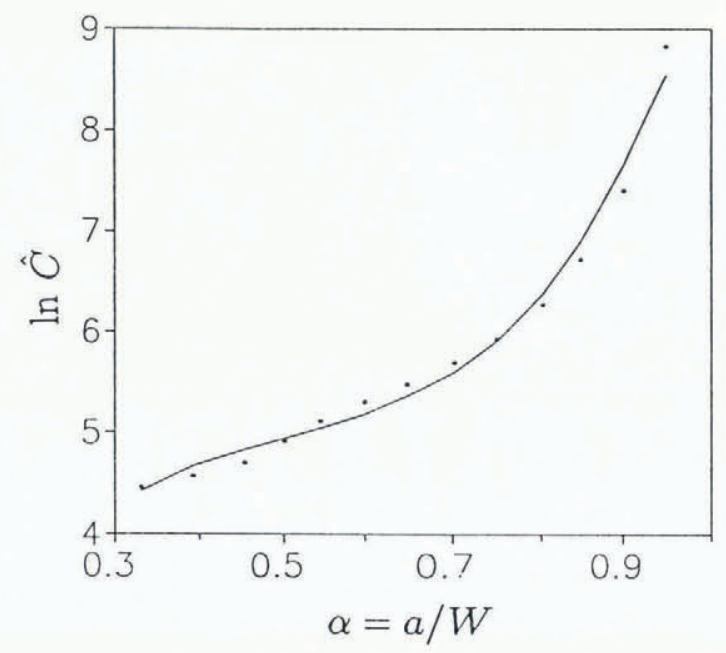

Fig. 2. Experimental load-point $S R C N$ compliance for $A_{\mathrm{L}} / B=0.27$ plotted in $a \ln C^{\prime}$ versus $\alpha$ curve.
The critical crack length $\alpha_{\mathrm{c}}$ is found by interpolating and extrapolating the values from Shannon and others (1982); see Stehn (1990). Using the technique of Ouchterlony (1985), this results in:

$$
\alpha_{\mathrm{c}}=0.570\left(1-0.068 \frac{\Delta W}{B}+0.636 \frac{\Delta a_{0}}{B}\right)
$$

where, for the variations in $W$ and $a_{0}$, we have:

$$
\frac{\Delta W}{B}=\frac{W}{B}-1.45, \quad \frac{\Delta a_{0}}{B}=0.481-\frac{a_{0}}{B} .
$$

The initial dimensionless compliance, $C_{0}{ }^{\prime}$ when $\alpha=\alpha_{0}$, has been given by Ouchterlony (1989b)

$$
C_{\mathrm{o}}^{\prime}=84.5\left(1+2.901 \frac{\Delta a_{\mathrm{o}}}{B}+2.527\left(\frac{t}{B}-0.012\right)\right)
$$

where $t$ is the chevron-notch thickness. The elastic modules when bending the specimen material is thus given by:

$$
E^{\prime}=\frac{C_{\mathrm{o}}^{\prime}}{C_{\mathrm{o}} B}
$$

where $C_{o}$ is the initial tangent slope.

\section{FIFT - A FIELD INSTRUMENT FOR FRACTURE- TOUGHNESS TESTS ON ICE}

A complete facility for fracture-toughness testing on ice should contain two separate parts: a laboratory test facility and field test equipment. An in situ test can never give more accurate results than the laboratory counterpart. However, ice-engineering problems require "real" ice properties measured in the field. In line with that developed by Fransson and others (1989a, b), a field instrument for fracture-toughness tests on ice has been developed by Stehn and Fransson (1989) and Stehn (1990). The key design requirements for FIFT were:

The test procedure must be simple enough for two men to handle in the field. No complex load frame or power supply were to be required.

A high system stiffness. Naturally, it must be stiffer than the elastic modulus of ice, $E \approx 5-9 \mathrm{GPa}$, but also stiff enough to present a loading condition favorable to stable crack growth.

The design of FIFT is shown in Figure 3. FIFT has two basic components: a field instrument and a dataacquisition system. The length of the field instrument is $430 \mathrm{~mm}$. Together with the portable data-acquisition system, the total weight is about $15 \mathrm{~kg}$. Field conditions are wet and cold, so all temperature-sensitive equipment (amplifier, data-acquisition unit and the batteries) is placed inside an insulated box that is heated with a simple chemical heating system.

In principle, the instrument consists of a house attached to a hydraulic load cushion. The house is a threaded, hollow pipe filled with fluid. A simple handheld electrical drilling machine is used to rotate a screw that via a piston depresses the fluid from the house into the load cushion. The load cushion is fitted into a slot of the SRCN specimen. This is schematically shown by the 

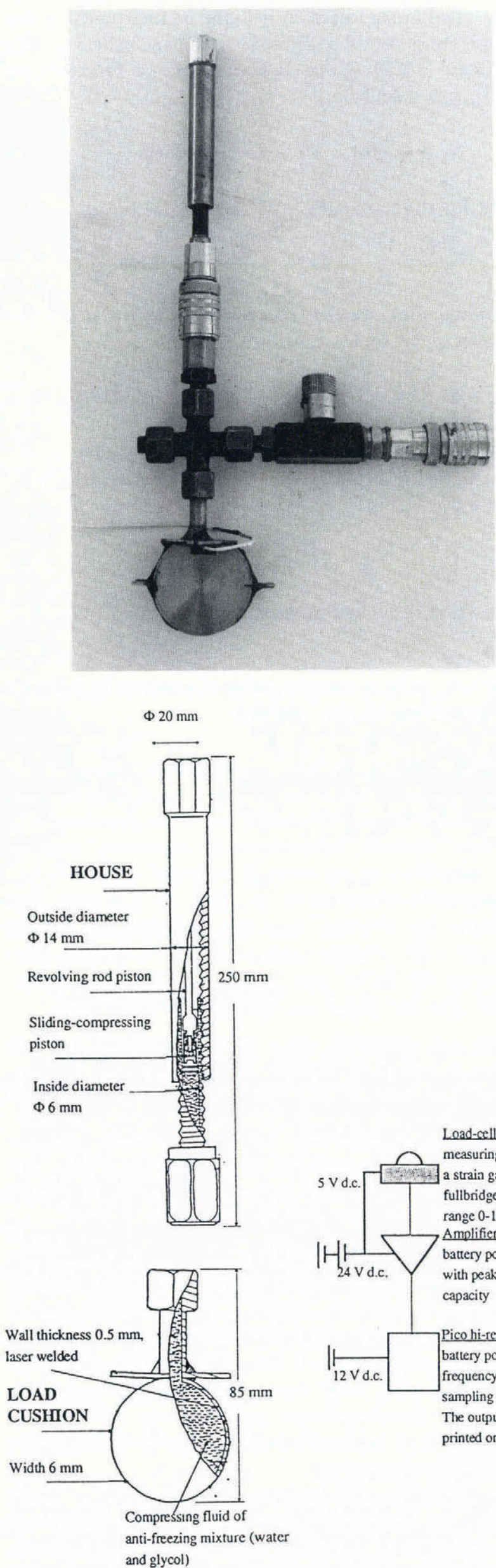

Fig. 3. Layout of FIFT: general outline, detail of loading arrangement and detail of cushion with a schematic of the data-acquisition system. shaded, circular area in Figure 1. When the fluid (antifreezing mixture of water and glycol) is compressed into the cushion, one side stays motionless while the other expands, linearly, and applies force on the specimen. The drilling machine develops a torque of $11 \mathrm{Nm}$ and rotates at $1100 \mathrm{rpm}$. This is powerful enough for the loading rate to be fairly constant at around $200 \mathrm{~N} \mathrm{~s}^{-1}$. The load is measured directly via a small $1000 \mathrm{~N}$ load cell (Kyowa LM-100KA).

Several tests have been performed in cold rooms to check the reliability of the instrument. The cushion is designed to sustain very high pressures and to verify this it was subjected to a pressure of $800 \mathrm{kPa}$. The cushion did not leak or burst. The reaction at different temperatures was examined, with emphasis on the function of the load cell and load housing. No drastic changes were found.

\section{EXPERIMENTAL PROCEDURE AND RESULTS}

These fracture tests were conducted on ice from the Gulf of Bothnia on three separate occasions, February-March 1988, April 1990 and January-April 1991. The ice from 1988 was used in preliminary FIFT tests. The grain structure of the ice was determined from thin vertical and horizontal sections. The structure was found to be predominantly granular, with layers of columnar ice 15-20 cm apart (see Fig. 4). This indicates that the ice was rafted. Some samples were collected and tested at lighthouses further out in the Gulf and they had a columnar structure. Two samples, No. 5.3 and 5.4 (see Table 1), had grown under calm conditions and consisted of very large columnar grains. The specimens were made from cores with a diameter of $193 \mathrm{~mm}$. The SRCN specimen slot with its chevron notch was machined with a bandsaw and a milling machine. In the field, the specimens were manufactured with a hand-held saw and milling machine. In all cases, except test No. 4.8, 5.3 and 5.4, the crack front was perpendicular to the direction of the crystal growth. For the tests mentioned, the crack front was parallel to the columnar grains, i.e. the same as radial cracking. Average grain-size was estimated using the mean linear intercept method and

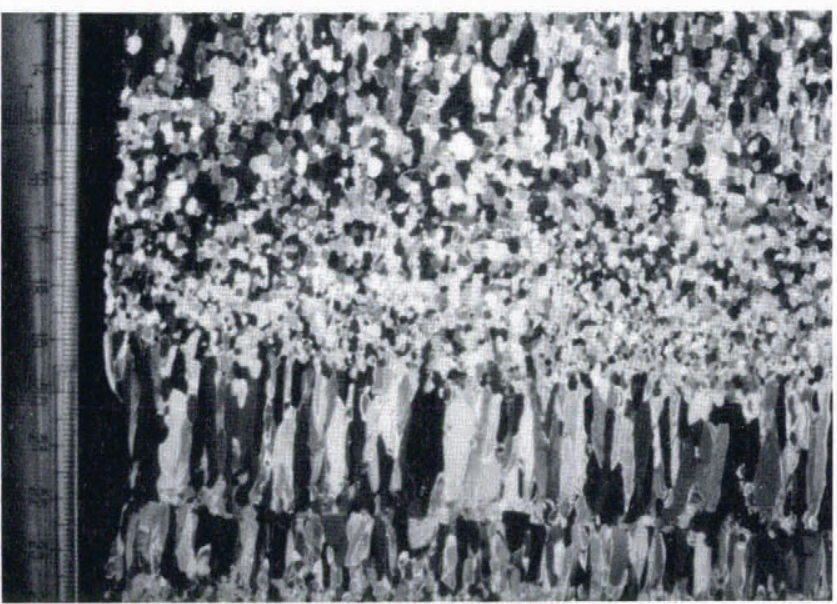

Fig. 4. Vertical thin section photographed between crossed polaroids. 
Table 1. Test data and results for sea-ice SRCN specimens

\begin{tabular}{|c|c|c|c|c|c|c|c|c|}
\hline No. & 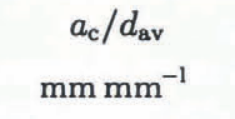 & $\begin{array}{c}S \\
\text { ppt }\end{array}$ & $\begin{array}{c}\mathrm{T} \\
-{ }^{\circ} \mathrm{C}\end{array}$ & $\begin{array}{c}F_{\max } \\
\mathrm{N}\end{array}$ & $\begin{array}{l}t_{\mathrm{f}} \\
\mathrm{s}\end{array}$ & $\begin{array}{c}K_{\mathrm{Q}} \\
\mathrm{kPa} \mathrm{m}^{1 / 2}\end{array}$ & $\begin{array}{c}E \\
\mathrm{GPa}\end{array}$ & $\begin{array}{c}G_{\mathrm{Ic}} / G_{\mathrm{Q}} \\
\mathrm{J} \mathrm{m}^{-2}\end{array}$ \\
\hline 1.1 & $199 / 2.7^{8}=74$ & 0.12 & 5.0 & 287.0 & 2.0 & 98 & 5.9 & $1.2 / 1.6$ \\
\hline $1.2^{\mathrm{t}}$ & $163 / 1.7^{g}=96$ & 0.14 & 5.0 & 208.0 & 2.3 & 64 & 3.8 & $0.6 / 1.1$ \\
\hline 1.3 & $198 / 3.7^{8}=54$ & 0.08 & 5.0 & 329.8 & 1.9 & 112 & 7.6 & $1.2 / 1.6$ \\
\hline 1.4 & $194 / 2.9^{g}=67$ & 0.07 & 5.0 & 299.7 & 2.0 & 103 & 5.3 & $1.4 / 2.0$ \\
\hline 1.5 & $192 / 3.0^{g}=64$ & 0.09 & 5.0 & 325.4 & 2.0 & 108 & & \\
\hline 1.6 & $186 /-$ & 0.08 & 7.5 & 339.4 & 1.7 & 97 & & \\
\hline 1.7 & $175 /-$ & 0.23 & 7.5 & 309.0 & 1.6 & 88 & & \\
\hline 1.8 & $198 /-$ & 0.33 & 7.5 & 241.3 & 2.3 & 70 & & \\
\hline 2.1 & $175 / 4.6^{g}=38$ & 0.22 & 10.0 & 294.4 & 1.4 & 87 & 6.4 & $0.6 / 1.2$ \\
\hline 2.2 & $169 / 3.3^{8}=41$ & 0.22 & 10.0 & 273.2 & 2.8 & 95 & 6.1 & $0.8 / 1.5$ \\
\hline 2.3 & $177 / 3.9^{g}=45$ & 0.31 & 10.0 & 266.3 & 1.5 & 73 & 5.4 & $0.6 / 1.0$ \\
\hline 2.4 & $171 / 4.4^{g}=39$ & 0.24 & 10.0 & 246.6 & 1.4 & 85 & 8.7 & $0.5 / 0.8$ \\
\hline 3.1 & $178 / 1.9^{g}=94$ & 0.11 & 5.1 & 254.2 & 1.2 & 73 & & \\
\hline 3.2 & $183 / 1.9^{g}=96$ & 0.30 & 4.1 & 178.9 & 1.3 & 54 & & \\
\hline 3.3 & $185 / 3.3^{g}=56$ & 0.05 & 3.8 & 357.2 & 2.2 & 107 & & \\
\hline 3.4 & $203 / 2.0^{g}=102$ & 0.17 & 4.1 & 257.6 & 1.7 & 80 & & \\
\hline 3.5 & $178 / 3.4^{g}=52$ & 0.31 & 3.8 & 192.7 & 1.5 & 55 & & \\
\hline $3.6^{\mathrm{t}}$ & $197 / 1.4^{g}=141$ & 0.12 & 4.2 & 60.6 & 2.3 & 21 & & \\
\hline 3.7 & $179 / 2.8^{8}=64$ & 0.15 & 4.3 & 284.2 & 1.2 & 82 & & \\
\hline 3.8 & $176 / 1.8^{8}=98$ & 0.22 & 3.5 & 167.2 & 1.5 & 48 & & \\
\hline 3.9 & $181 / 3.3^{8}=55$ & 0.13 & 3.2 & 328.6 & 1.8 & 94 & & \\
\hline 3.10 & $179 / 1.9^{8}=94$ & 0.31 & 3.8 & 172.0 & 1.3 & 53 & & \\
\hline 3.11 & $180 / 1.6^{\mathrm{g}}=112$ & 0.41 & 4.2 & 118.0 & 1.2 & 33 & & \\
\hline 3.12 & $181 / 2.0^{g}=90$ & 0.38 & 2.1 & 152.9 & 1.2 & 46 & & \\
\hline 4.1 & $167 / 3.3^{8}=51$ & 0.02 & 2.0 & 408.8 & 1.5 & 137 & & \\
\hline 4.2 & $155 / 4.3^{g}=36$ & 0.01 & 2.9 & 588.2 & 1.6 & 143 & & \\
\hline 4.3 & $173 / 19.8^{c}=9$ & 0.06 & 5.3 & 350.6 & 1.8 & 112 & & \\
\hline 4.4 & $168 / 22.2^{c}=8$ & 0.09 & 3.4 & 481.8 & 2.0 & 153 & & \\
\hline 4.5 & $167 / 30.0^{c}=6$ & 0.02 & 3.4 & 503.8 & 2.1 & 168 & & \\
\hline 4.6 & $159 / 17.5^{c}=9$ & 0.02 & 2.9 & 349.9 & 1.8 & 103 & & \\
\hline 4.7 & $160 / 10.8^{c}=15$ & 0.12 & 4.7 & 301.1 & 1.4 & 84 & & \\
\hline 4.8 & $167 / 6.4^{g}=26$ & 0.08 & 1.2 & 375.2 & 1.2 & 112 & & \\
\hline 5.1 & $157 / 52.9^{c}=3$ & 0.05 & 8.9 & 482.5 & 1.2 & 127 & & \\
\hline 5.2 & $163 / 4.7^{8}=35$ & 0.11 & 9.0 & 369.7 & 1.0 & 111 & & \\
\hline 5.3 & $158 / 90^{\mathrm{mc}}=2$ & 0.20 & 9.0 & 304.9 & 1.3 & 83 & & \\
\hline 5.4 & $154 / 100^{\mathrm{mc}}=2$ & 0.04 & 9.0 & 276.8 & 0.7 & 72 & & \\
\hline 6.1 & $158 / 2.7^{g}=59$ & 0.04 & 10.0 & 475.6 & 1.4 & 136 & 3.1 & $4.1 / 6.0$ \\
\hline 6.2 & $155 / 2.7^{g}=57$ & 0.04 & 10.0 & 316.5 & 1.4 & 83 & 4.2 & $1.4 / 1.6$ \\
\hline 6.3 & $155 / 3.1^{8}=50$ & 0.10 & 10.0 & 356.3 & 3.0 & 99 & 7.6 & $1.0 / 1.3$ \\
\hline 6.4 & $153 / 2.8^{8}=55$ & 0.04 & 10.0 & 313.5 & 3.8 & 73 & 3.3 & $2.0 / 1.6$ \\
\hline 6.5 & $152 / 2 \cdot 1^{\mathrm{g}}=72$ & 0.02 & 10.0 & 516.4 & 1.0 & 124 & 7.3 & $2.4 / 2.1$ \\
\hline 6.6 & $152 / 3.4^{8}=45$ & 0.04 & 10.0 & 377.8 & 1.5 & 88 & 4.0 & $2.5 / 1.9$ \\
\hline
\end{tabular}

${ }^{\mathrm{t}}$ transverse failure (see text); ${ }^{\mathrm{g}}$ granular; ${ }^{\mathrm{c}}$ columnar; ${ }^{\mathrm{mc}}$ monocrystal.

ranged from 1.6 to nearly $100 \mathrm{~mm}$. The ice was rather porous as demonstrated by the average densities of $875.5 \pm 7 \mathrm{~kg} \mathrm{~m}^{-3}$ at $-1^{\circ} \mathrm{C}$ for series $1,883.4 \pm 22 \mathrm{~kg} \mathrm{~m}^{-3}$ at $-5^{\circ} \mathrm{C}$ for series $2,883.2 \pm 5 \mathrm{~kg} \mathrm{~m}^{-3}$ at $-3^{\circ} \mathrm{C}$ for series 3 and $894.8 \pm 9 \mathrm{~kg} \mathrm{~m}^{-3}$ at $-10^{\circ} \mathrm{C}$ for series $4-6$. The temperatures during the tests varied between $-10^{\circ}$ and $-1.5^{\circ} \mathrm{C}$. Loading rates were difficult to estimate but the time to fracture ranged from 0.7 to $3.8 \mathrm{~s}$.

After testing, the dimensions of the specimens were measured and each specimen was carefully examined. The temperature was measured immediately after the test in a small hole drilled into the specimen approximately at $a_{\mathrm{c}}$. With the exception of No. 1.2 and 3.6, the specimens cracked along the chevron notch. In the above-mentioned tests, a transverse failure occurred before a proper evaluation of the fracture toughness could be made. This appears as a broken "arm" where the crack had veered off from the chevron plane and out into the arm. 
Ouchterlony (1985) has described this phenomenon with regard to rock specimens.

The fracture surfaces were visually examined. The critical crack length was clearly visible in most cases. Furthermore, very interesting features of the fracture of sea ice could be seen, just by the naked eye. In the upper triangular part of the notch the surface had a wavy appearance showing evidence of conchoidal brittle fracture. The lower part of the chevron notch showed a smoother surface with horizontal lines extending over the whole width of the notch. The lines came closer together towards the bottom of the specimen. This suggests that the crack was propagating through the mechanism of continuous cleavage fracture, in other words, through the mechanism of irregular brittle-crack growth (crackjumping). This behavior has been observed on freshwater ice and cold saline ice (see Introduction). It is recognized that these observations are only based on what could be detected visually.

The $\delta_{\mathrm{F}}$ was measured, in some tests in series 1 and 2, with two linear variable displacement transducers (LVDTs). In series $6, \delta_{\mathrm{F}}$ was measured using two clip gauges. The load and load-point displacement for series 1 through 3 were measured using a $20 \mathrm{MHz}$ storage oscilloscope, while for series 4, 5 and 6 the signals were processed by a 16 bit analog-to-digital converter, set in a DARTEC testing machine in series with a $386 \mathrm{SX}$ microcomputer. Data were received at the rate of 300 readings s ${ }^{-1}$. The load and $\delta_{\mathrm{F}}$ vs time and the load vs $\delta_{\mathrm{F}}$ results for test No. 6.2 are shown in Figure 5. The crack growth commences at the distinct change of slope, for both $F$ and $\delta_{\mathrm{F}}$, as shown in Figure 5a. This is a typical
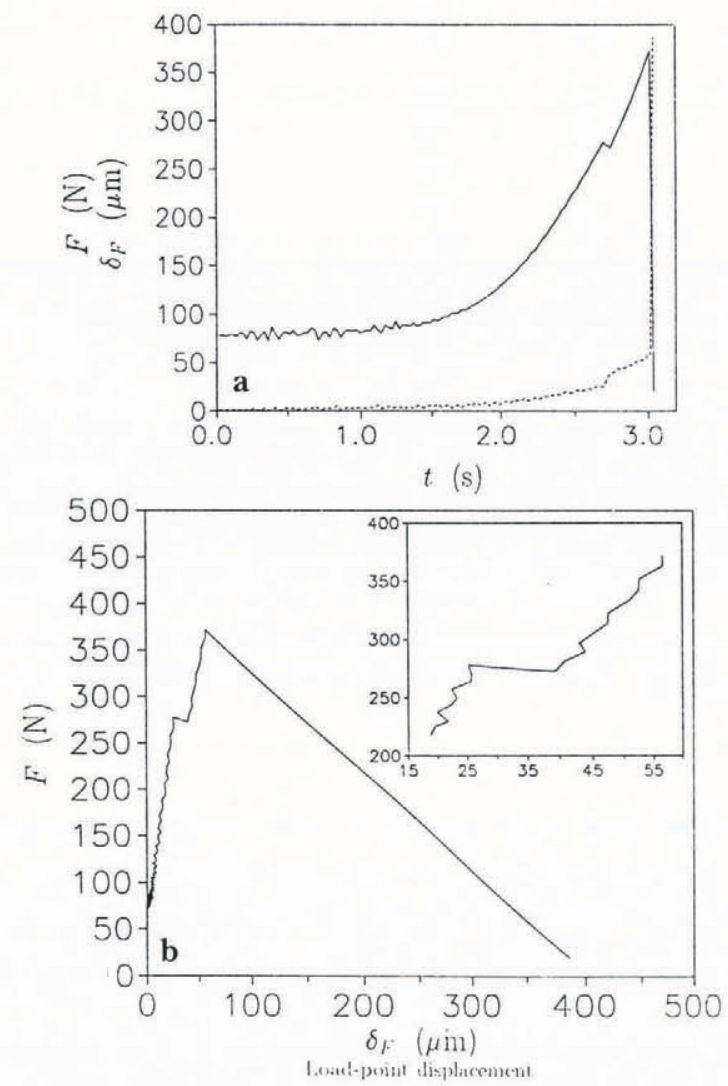

Fig. 5. a. $F$ and $\delta_{\mathrm{F}}$ vs time. b. $F-\delta_{\mathrm{F}}$ record for test No. 6.2 . feature of all $F-\delta_{\mathrm{F}}$ records, where in some cases evidence of non-linear processes appeared as a nonlinear slope after the crack initiation. Figure $5 \mathrm{~b}$ also shows crack initiation in more detail.

The experimental results from the 42 fracture tests are summarized in Table 1. Each test is identified by a group and a sequence number followed by an $a_{\mathrm{c}} / d_{\mathrm{av}}$ ratio, i.e. critical crack length/average grain-size. $S$ is the salinity deduced from measured meltwater conductivity at $20^{\circ} \mathrm{C}$, $T$ is the test temperature, $F_{\max }$ is identified as the maximum load from load vs time records, $t_{\mathrm{f}}$ is the time to failure and $E$ is the elastic modulus in bending based on the initial compliance. $G_{\text {Ic }}$, the energy-release rate, is calculated according to Equation (1) and $G_{\mathrm{Q}}=K_{\mathrm{Q}}{ }^{2} / E$ is the apparent critical energy-release rate.

It is important to note that the grain-size, temperature and loading rate were not kept constant between the tests and this causes a significant scatter in the results. However, similarities between $G_{\mathrm{Ic}}$ and $G_{\mathrm{Q}}$ indicate that this low-saline granular ice is quite isotropic and homogeneous, and the selected specimen size was probably large enough, compared to the relatively small average grain-size, not to contribute to the scatter.

Figure 6 shows the apparent fracture toughness vs the temperature. Figure 7 shows the apparent fracture toughness vs the average grain-size. In this figure we see that $K_{\mathrm{Q}}$ rises to a maximum and then subsequently decreases as $d_{\mathrm{av}}$ increases. Dempsey and Wei (1988)

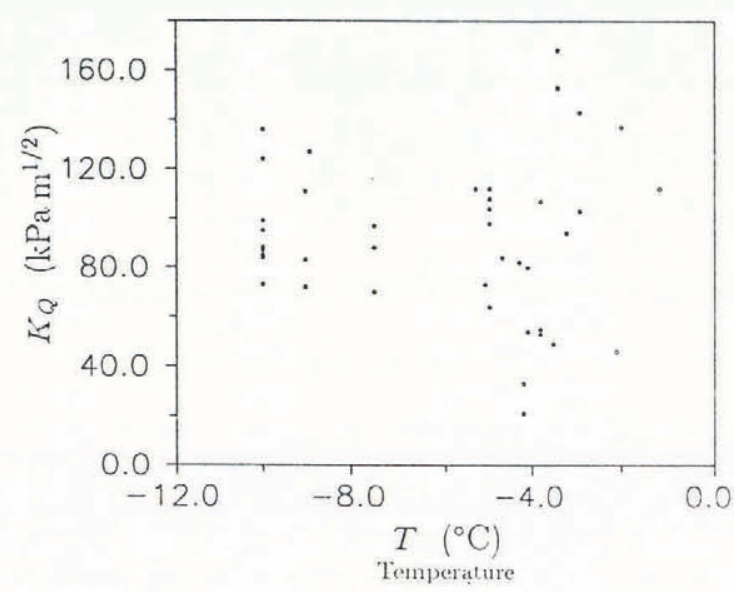

Fig. 6. Apparent fracture toughness vs temperature.

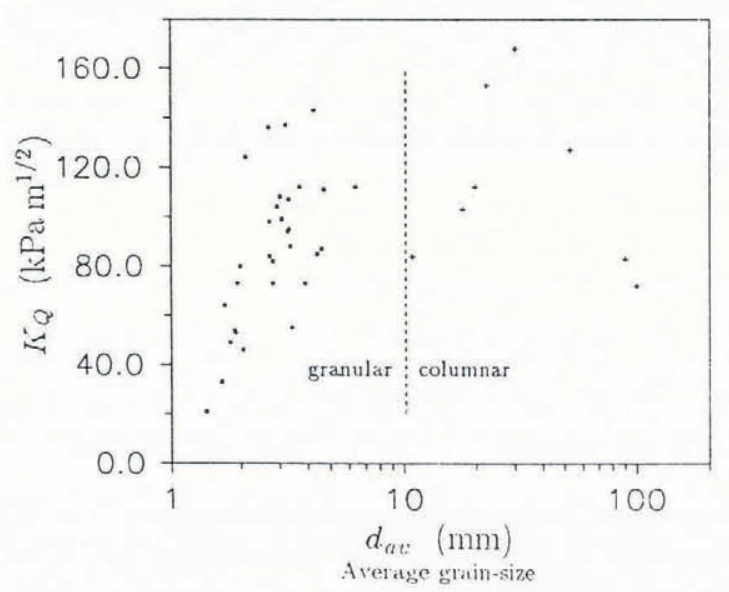

Fig. 7. Apparent fracture toughness vs average grain-size. 
discussed this type of grain-size dependence for ice and Rice and others (1978) for non-cubic ceramics. The break point appears to depend on a crystal structure-thermal expansion and strain-mismatch effect.

\section{STABLE CRACK GROWTH}

Various parameters affect crack growth: load control (displacement or stroke control), loading rate, specimen geometry (reflected through its $G$ ) and the material. Stable crack growth, in the situation of continuous quasistatic growth, has not been obtained in ice. Instead, crack-jumping is observed where the crack grows abruptly over a distance and then arrests (DeFranco and Dempsey, 1990, 1991; Parsons and others, 1988, 1989) on both fresh-water and sea ice. This behavior may be attributed to a decreasing crack-growth resistance of the ice.

In stable crack propagation, crack velocity is low and the extension may be tracked visually. Unstable crack propagation is associated with an abrupt load drop at fracture and with a crack that accelerates quickly generates considerable kinetic energy. Crack-growth stability requires that the crack driving force and the crack-growth resistance are equal. On the other hand, in dynamic conditions, crack-growth stability occurs when the rate of change in the crack driving force is equal to the sum of the rate of change in the resistance to fracture and the kinetic energy. This type of simplified dynamic energy-rate balance pre-supposes the following: the displacements and crack area are the same as for static conditions and the elastic crack speed is low so that the crack propagates under continuous quasistatic conditions. The requirements for stable crack growth may thus be formulated as:

$$
G=R+\frac{\partial H}{\partial A} \quad \text { and } \quad \frac{\partial G}{\partial A}=\frac{\partial R}{\partial \Delta A}+\frac{\partial^{2} H}{\partial A^{2}}
$$

where $A$ denotes the crack area and $H$ is the specimen's kinetic energy. For quasistatic cracking, the rate of change in the specimen's kinetic energy $(\partial H / \partial A)=0$.

Stable crack propagation may be quantified using the concept of geometric stability factor (gsf) (Mai and Atkins, 1980). If the test geometry has an adequately negative gsf, it should be capable of coping with the observed $\partial R / \partial \dot{a}$ negative characteristics of ice. By the use of Equation (1), differentiated with respect to $A$ and Equation (10), the normalized gsf for a displacement controlled test on the SRCN geometry is:

$$
\begin{aligned}
\frac{W^{2}}{R} \frac{\partial G}{\partial A} \geq & f\left(W / B, \alpha, \alpha_{\mathrm{o}}\right)\left(\frac{\mathrm{d}^{2} C^{\prime} / \mathrm{d} \alpha^{2}}{\mathrm{~d} C^{\prime} \mathrm{d} \alpha}-2 \frac{\mathrm{d} C^{\prime} / \mathrm{d} \alpha}{C^{\prime}}\right) \\
& -g\left(W / B, \alpha, \alpha_{\mathrm{o}}\right)
\end{aligned}
$$

where

$$
\begin{aligned}
f\left(W / B, \alpha, \alpha_{\mathrm{o}}\right)= & \left(\frac{W}{B}\right) \frac{1-\alpha_{\mathrm{o}}}{2 \alpha-\alpha_{\mathrm{o}}} \\
g\left(W / B, \alpha, \alpha_{\mathrm{o}}\right)= & \left(\frac{W}{B}\right) \frac{\left(1-\alpha_{\mathrm{o}}\right)^{3}}{\alpha\left(\alpha-\alpha_{\mathrm{o}}\right)} . \\
& \frac{\left(2 \alpha-\alpha_{\mathrm{o}}\right)\left(3 \alpha-\alpha_{\mathrm{o}}\right)}{\left[\left(\alpha-\alpha_{\mathrm{o}}\right)\left(1-\alpha_{\mathrm{o}}\right)+\alpha\left(\alpha-\alpha_{\mathrm{o}}\right)^{2}\right]^{2}} .
\end{aligned}
$$

The third term on the righthand side of Equation (11) arises from the effect of the increasing crack-front length with crack growth. The above concept has been used both for the double torsion (DT) specimen, (Parson and others, 1989) and for the reverse tapered crack line wedge loaded (RTCLWL) geometry developed by DeFranco and Dempsey (1991) * Figure 8 shows a plot of the normalized gsf for the DT, RTCLWL and SRCN (cf. DeFranco and Dempsey, 1991). It is instructive to note that the geometry of every specimen shows negative gsf for all crack lengths. The RTCLWL and the SRCN both promote stable, even for a strong rate sensitivity of crack propagation, crack growth.

Assuming that the underlying independent test variable is time, then in a displacement controlled test $\delta_{F}=\dot{\delta}_{F} t$ and $F=F\left(\delta_{\mathrm{F}}\right)$. If the compliance is differentiated under the conditions of steady-state crack growth and the assumption that crack length $a$ increases monotonically with $\delta_{\mathrm{F}}$, the result is:

$$
\dot{C}=\frac{\delta_{F}}{F}\left(1-\frac{\partial F}{\partial \delta_{\mathrm{F}}} C\right)=\frac{\dot{a}_{\mathrm{e}}}{W B E} \frac{\partial C^{\prime}}{\partial \alpha} .
$$

Hence by using $F=F_{\max }$ according to Equation (3), the estimated crack velocity for the SRCN specimen can be written as:

$$
\dot{a}_{\mathrm{e}}=\frac{Y_{\min }^{\prime \prime}}{\partial C^{\prime} / \partial \alpha} \frac{E \sqrt{W}}{K_{\mathrm{Q}}}\left(1-\frac{\partial F}{\partial \delta_{\mathrm{F}}} C\right) \dot{\delta}_{\mathrm{F}} .
$$

It is important to note that the $\left(F-\delta_{\mathrm{F}}\right)$ plot is of paramount importance since $E, \partial F / \partial \delta_{\mathrm{F}}$ and $\dot{\delta}_{\mathrm{F}}$ directly rely upon it. $\partial F / \partial \delta_{\mathrm{F}}$ is taken as the slope immediately prior to the maximum load. This simplification is reasonable since the critical-toughness value is representative in a relatively wide region around the load maximum. Another simplification is to assume a "smooth load maximum" implying that $\partial F / \partial \delta_{\mathrm{F}}=0$ at $F=F_{\max }$. This yields an estimated crack velocity:

$$
\dot{a}_{\mathrm{e}}=\frac{Y_{\min }^{\prime \prime}}{\partial C^{\prime} / \partial \alpha} \frac{E \sqrt{W}}{K_{\mathrm{Q}}} \dot{\delta}_{\mathrm{F}} .
$$

A smooth load maximum did not occur in any of the tests, as is evident from the typical test shown in Figure 5. By making this kind of simplification, the crack speed is overestimated by $22 \%$ on average.

A way of quantitatively determining the stability and dynamics of the calculated crack velocities, in terms of imparted kinetic energy, has been given by Gurney and Ngan (1971). They set up a criterion for stability where only $5 \%$ of the stored strain energy is transformed into the

\footnotetext{
*It may be of passing interest to recognize that a smaller thickness has a positive effect on crack-growth stability as can be found by differentiating the requirements for stable crack growth with respect to $A$ instead of $a$ (that is only applicable for specimens with constant crack widths). The original gsf equations for the DT and RTCLWL specimens, presented in Figure 8, were multiplied by the ratio $(W / b)$. With this alternative formulation, it can be readily seen that a thin specimen promotes crack-growth stability.
} 


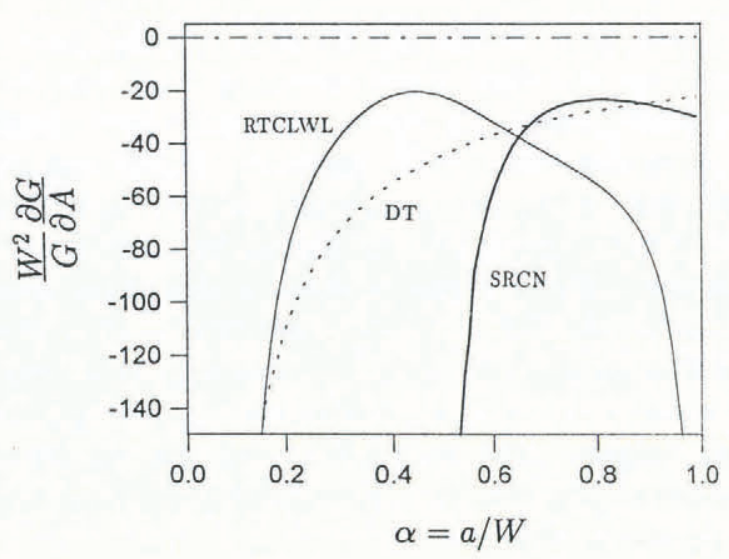

Fig. 8. Normalized gsf vs $\alpha$.

kinetic energy of the specimen. By using Equation (10) and the simple one-dimensional SRCN beam-theory model in Stehn (1992) recalculated according to Equation (10), a crack velocity when kinetic energy is not negligible is calculated as:

$$
\dot{a}_{\mathrm{H}} \approx 0.64 c
$$

where $c=(E / \rho)^{1 / 2}$ is the speed of a longitudinal wave in the ice beam. An actual crack velocity can therefore be compared with $\dot{a}_{\mathrm{H}}$ to determine whether the crack is growing in a stable manner by the $5 \%$ definition quoted above.

The load-point displacement rate, the crack velocity calculated from Equation (14) and $\Delta$, the percentage of the crack speed going into kinetic energy, i.e. $\dot{a}_{\mathrm{e}} / \dot{a}_{\mathrm{H}}$, are given in Table 2.

The values in this table for crack velocity exhibit a large variability, something not uncommon for ice parameters. The average value for crack velocity is found to be $\dot{a}_{\mathrm{e}}=20 \pm 11 \mathrm{~m} \mathrm{~s}^{-1}$. Parsons and others (1987) also obtained a velocity of approximately $20 \mathrm{~m} \mathrm{~s}^{-1}$ measured on first-year sea-ice double cantilever

Table 2. Estimated crack velocities

\begin{tabular}{cccc} 
No. & $\begin{array}{c}\dot{\delta}_{\mathrm{F}} \\
\mathrm{mm} \mathrm{s}^{-1}\end{array}$ & $\begin{array}{c}\dot{a}_{e} \\
\mathrm{~m} \mathrm{~s}^{-1}\end{array}$ & $\begin{array}{c}\Delta \\
\%\end{array}$ \\
\hline
\end{tabular}

\begin{tabular}{rrrl}
1.1 & 10 & 9 & 0.5 \\
1.2 & 14 & 30 & 2.2 \\
1.3 & 15 & 12 & 0.6 \\
1.4 & 12 & 9 & 0.6 \\
2.1 & 19 & 37 & 2.2 \\
2.2 & 6 & 10 & 0.6 \\
2.3 & 18 & 31 & 1.9 \\
2.4 & 6 & 16 & 0.8 \\
6.1 & 23 & 23 & 1.9 \\
6.2 & 12 & 19 & 1.3 \\
6.3 & 3 & 7 & 0.4 \\
6.4 & 30 & 39 & 3.2 \\
6.5 & 11 & 20 & 1.1 \\
6.6 & 9 & 15 & 1.1 \\
& & & \\
\hline
\end{tabular}

beams. By the Gurney and Ngan definition, it is clear that stable crack propagation is occurring. A multipleregression analysis performed on the data revealed that $\dot{\delta}_{\mathrm{F}}$ had the greatest influence on crack velocity, which, in view of the theoretical work by Sigl (1991) on brittle solids, should be the case. The experimental values are given in Figure 9 as $K_{\mathrm{Q}}$ vs estimated crack velocity. The scatter in this figure is substantial.

\section{POROSITY EFFEGTS ON FRAGTURE TOUGHNESS}

Pores in ice, as in other brittle materials, may affect the mechanical properties. Pores occur naturally during formation of the sea-ice cover in the form of air and brine pockets. Air bubbles are comparatively large with a heterogeneous spatial distribution. To determine the actual distribution and size, back-lit sections $(5-8 \mathrm{~mm}$ thick) were studied using several specimens. The bubbles were of the same size as the granular grains, i.e. 0.5$4 \mathrm{~mm}$ and 5-20 $\mathrm{mm}$ apart. However, sometimes the air bubbles were arranged in vertical bubble pipes (typically

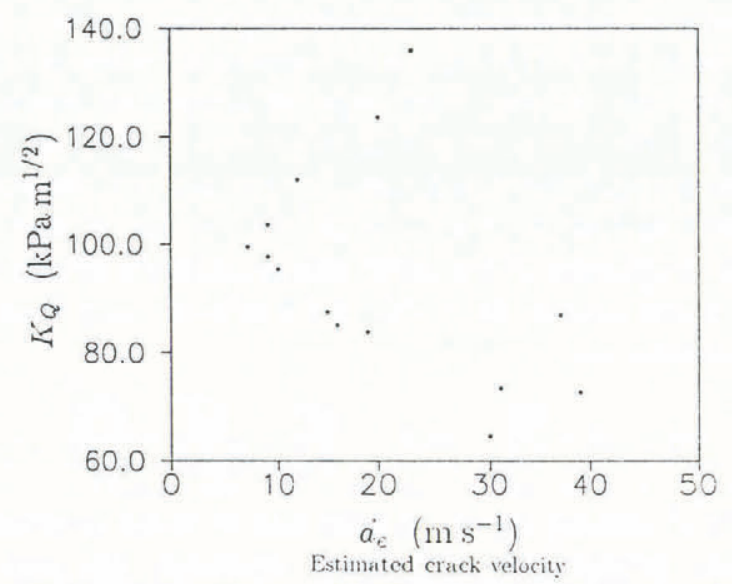

Fig. 9. Apparent fracture toughness vs estimated crack velocity.

in the granular-columnar boundary zone). This may have had a considerable weakening effect on the ice. The brine pockets showed a completely different distribution. The sub-structure of sea ice shows pure ice platelets, about $0.5 \mathrm{~mm}$ thick, separated by layers of brine pockets. The important influence of the sub-structure of saline ice has been shown by DeFranco and others (1991). For cold $\left(-25^{\circ} \mathrm{C}\right)$ saline ice SENB tests, using four-point bending, the observed fracture developed parallel to the long directions of the ice platelets in most of the cases.

The influence of porosity on cold, columnar sea ice reported to date has been mentioned in the works by Vaudrey (1977), Timco and Frederking (1983) and Urabe and others (1980), and is shown in Figure 10b.

An assumption that may be made is that the crack will seek the path having the minimum solid area, i.e. the maximum area of porosity. In this case, fracture energy is proportional to the actual solid area fractured. This 

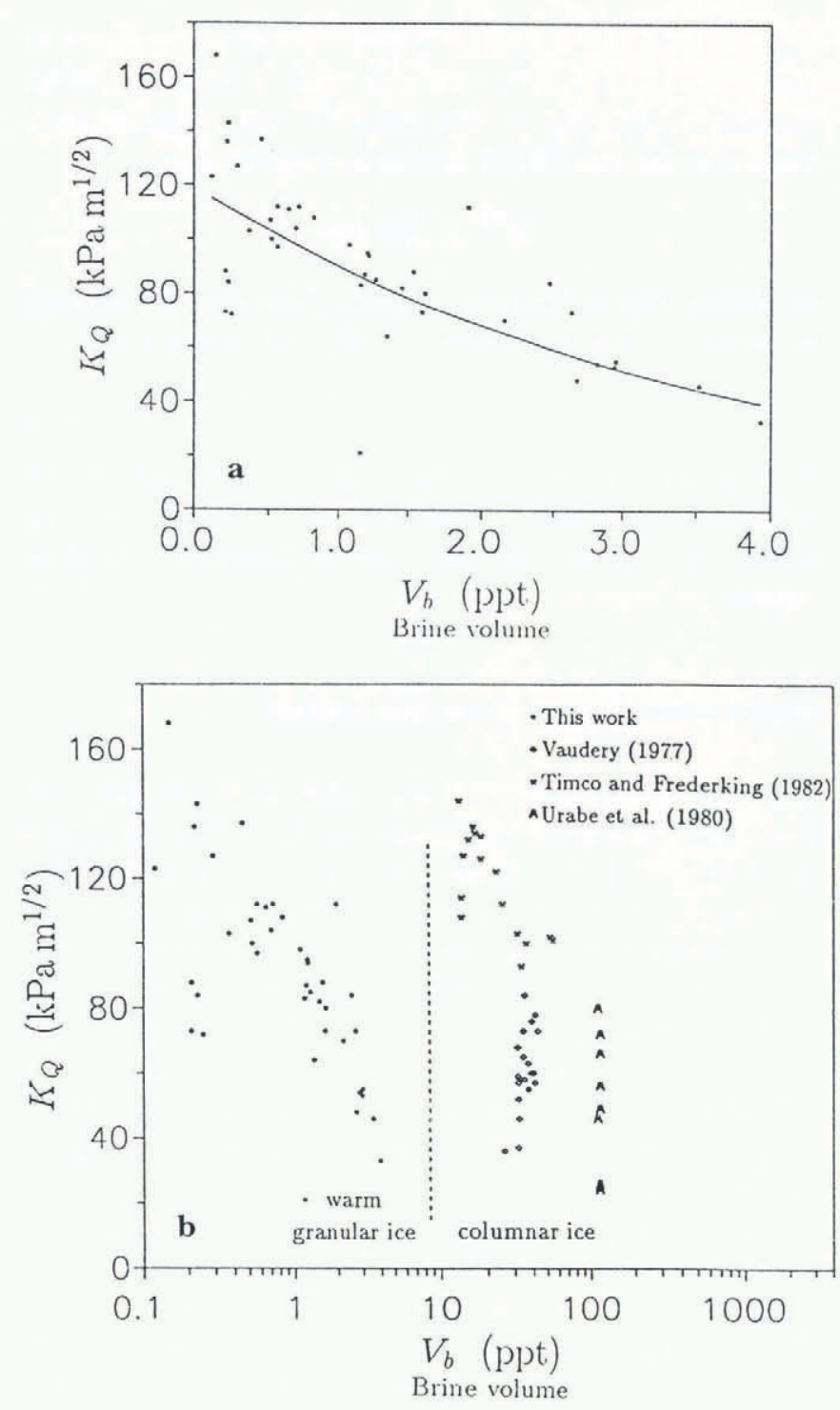

Fig. 10. Apparent fracture toughness vs brine volume. a. Experimental results. b. Previous investigations.

approach ${ }^{*}$ results in the non-linear porosity-dependent fracture toughness given by Rice (1977) in the following form, $K_{\mathrm{QP}}=K_{\mathrm{O}} \mathrm{e}^{-m \Psi}$, where $K_{\mathrm{QP}}$ is the apparent porous fracture-toughness, $K_{\mathrm{O}}$ is the toughness for zero porosity, $\Psi$, and $m$ is an empirical exponent which depends on pore location, shape and size. Knudsen (1959) found that experiments on porous aluminum, steel and iron follow this type of relationship and the same has been indicated by Rice and others (1978) for various ceramics.

A reasonable assumption is that for warm, spring sea ice, pore shapes are (air) spheres and (brine) cylinders. Following the discussion in Brown and others (1964), a composite $m_{c}$ value can be calculated where the contribution made by the two pore types is incorporated (see also Rice and others, 1978; Stehn, 1990). For each specimen, calculations of relative air and brine volume,

\footnotetext{
*Models by Kristic and Erickson (1987) and Goldstein and Osipenko (1991), assuming that the pores act as flaws, were tested but were discarded due to the physical assumptions they required.
}

$V_{\mathrm{b}}$ were carried out using the equations in Cox and Weeks (1983). Due to the distribution and hence influence of the different pores discussed above, it was assumed that the air pores only contribute to the total porosity but not as a fracture energy sink. The average of all 42 tests, gave $m_{\mathrm{c}}=0.28 \pm 0.13$. Thus, the theoretical model for the dependence of the brackish sea-ice apparent fracture toughness on porosity, in form of brine volume, becomes:

$$
K_{\mathrm{QP}}=K_{\mathrm{O}} \mathrm{e}^{-0.28 V_{\mathrm{b}}} \text {. }
$$

The resulting curve is plotted in Figure $10 \mathrm{a}$, where $K_{\mathrm{O}}=119 \mathrm{kPa}$ is determined from a regression analysis based on Equation (17).

Evidently, the experimental results are very well described by the theoretical relationship. The exponent $m_{\mathrm{c}}$ is related to the porosity characteristics. The numerical value found is interesting, since Rice (1977) showed that $m$ values in the range $0.1-0.4$ are connected with a homogeneous spatial distribution and shape of the pores and that pore location is important. This is consistent for brine in granular ice since the brine inclusions are in the form of fine pockets, evenly spread and concentrated around grain boundaries. This can be considerably more serious than pores located elsewhere. It should be noted that this model is only accurate for low brine-volume values, i.e. for brackish sea ice, since for $V_{\mathrm{b}} \approx 18$ ppt the model predicts zero strength.

\section{NOTCH SENSITIVITY-SIZE REQUIREMENTS FOR ICE SPEGIMENS}

According to Dempsey (1991), many of the previous studies on both fresh-water and sea ice have used subsized specimens that are notch-insensitive. If a specimen is to be referred to as notch-sensitive, the crack and uncracked ligament must be sufficiently long. The above study by Dempsey put forward analytical calculations regarding the dependence of the notch sensitivity and the brittleness on the specimen size. This approach provides a tool for a similar derivation for the SRCN specimen.

The peak nominal tensile stress, $\sigma_{\mathrm{n}}$, acting on the net section at failure, is derived assuming a linear stress distribution throughout the uncracked ligament as:

$$
\sigma_{\mathrm{n}}=\frac{F_{\max }}{W B} Z^{\prime \prime}\left(\alpha_{0}, \alpha_{\mathrm{c}}\right) \text {. }
$$

Strictly, $\alpha_{\mathrm{c}}=\alpha_{\mathrm{c}}\left(\alpha_{0}\right)$ but for $\alpha_{\mathrm{c}}=0.617$

$$
Z^{\prime \prime}=35.7 \frac{\left(\alpha_{0}^{2}-1.98 \alpha_{0}+0.83\right)}{\left(\alpha_{0}^{2}-1.62 \alpha_{0}+0.64\right)} .
$$

The ratio of $\sigma_{\mathrm{n}}$ to the tensile strength, $\sigma_{\mathrm{t}}$ becomes:

$$
\frac{\sigma_{\mathrm{n}}}{\sigma_{\mathrm{t}}}=\frac{K_{\mathrm{Q}}}{\sigma_{\mathrm{t}} \sqrt{W}} \frac{Z^{\prime \prime}}{Y_{\min }^{\prime \prime}}=\beta_{\mathrm{f}} C_{\mathrm{nSR}}
$$

where $C_{\mathrm{nSR}}\left(\alpha_{\mathrm{o}}\right)$ is an SRCN geometry function. It is useful to note that $\beta_{\mathrm{f}}$ is related to the characteristic length, introduced by Hillerborg and others (1976), as $\beta_{\mathrm{f}}^{2} \equiv l_{\mathrm{ch}} / W=E^{\prime} G_{\mathrm{Ic}} / W \sigma_{\mathrm{t}}^{2}$. The characteristic length may be looked upon as a measure of the brittleness of a material, since it relates the crack-resistance energy to the elastic energy. Therefore, the parameter $\beta_{\mathrm{f}}$ could be 

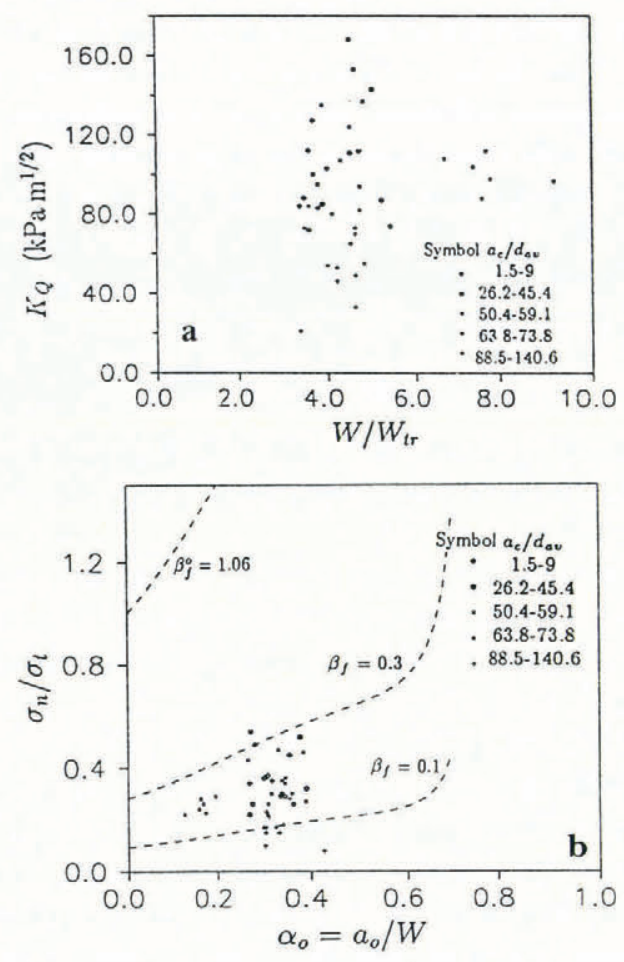

Fig. 11. a. Apparent fracture toughness vs specimen length to transitional length $\left(W / W_{\mathrm{tr}}\right) . b . \sigma_{\mathrm{n}} / \sigma_{\mathrm{t}}$ vs initial crack length to specimen length $\left(a_{o} / W\right)$. The dashed lines are lines of constant brittleness numbers, $\beta_{\mathrm{f}}$, where a lower brittleness number means increased notch sensitive. For $\beta_{\mathrm{f}}>\beta_{\mathrm{f}}^{o}$, a strength failure will occur prior to the attainment of a critical stress-intensity factor.

called a "brittleness number". Dempsey used $\beta_{\mathrm{f}}$ to propose a requisite LEFM specimen width as $\sigma_{\mathrm{n}} /$ $\sigma_{\mathrm{t}}<0.4$. But, and it is important to note this, he pointed out that no experimental work supports this and a thorough size-effect study, involving different grain-sizes, ice types, loading configurations, temperatures, etc., is required before this can be fully accepted.

Following the procedure in Dempsey, the apparent fracture toughness is plotted vs the ratio of the actual specimen length to the transitional length $\left(W / W_{\mathrm{tr}}\right)^{*}$ in Figure 11a. The largest ratio occurs for $a_{\mathrm{c}} / d_{\mathrm{av}} \approx 26-74$. This means that the appropriate initial crack length is $0.17 \leq a_{\mathrm{o}} / W \leq 0.28$. Using the above expressions, the ratio of $\left(\sigma_{n} / \sigma_{t}\right)$ is plotted versus the ratios of the initial crack length to the specimen length $\left(a_{\circ} / W\right)$ in Figure $11 \mathrm{~b}$. It is clear that the specimens were sufficiently large, i.e. notch-sensitive enough, to keep the ratio $\sigma_{\mathrm{n}} / \sigma_{\mathrm{t}}$ below 0.4. In terms of Equation (20), it is equivalent to requiring that:

$$
W^{\infty} \geq\left(2.5 C_{\mathrm{nSR}}\right)^{2}\left(\frac{K_{Q}}{\sigma_{\mathrm{t}}}\right)^{2}
$$

where $W^{\infty}$ is the requisite LEFM size. Using the standard value of $Y_{\min }^{\prime \prime}$ and $\alpha_{0}=0.332$, the geometry function

"The transitional length is the size for which, if $W>W_{\mathrm{tr}}$, a fracture failure will occur. However, the requisite LEFM size is bigger than $W_{\mathrm{tr}}$ due, mainly, to conditions (B) and (C) in the Introduction.
$C_{\mathrm{nSR}}=1.633$. The tensile strength for fresh-water ice with $d_{\mathrm{av}}=4 \mathrm{~mm}=0.9 \mathrm{MPa}$ (Currier and Schulson, 1982). Assuming that $K_{\mathrm{Q}}=100 \mathrm{kPa} \mathrm{m}^{1 / 2}$, the required specimen size for the SRCN specimen is given by:

$$
W^{\infty} \geq 206 \mathrm{~mm}
$$

or, taking Figure $11 \mathrm{a}$ into account, given that the average grain-size within the largest $W / W_{\mathrm{tr}}$ ratios is $4.4 \mathrm{~mm}$ :

$$
W^{\infty} / d_{\mathrm{av}} \geq 47 \text {. }
$$

A clear picture depicted from Table 1 is that almost all, with the exception of the large columnar-grained ice tested, specimens fulfil the size requirement stated in Equation (22).

\section{DISCUSSION AND CONCLUSIONS}

The test system operates very satisfactorily in the field. Field and laboratory test programs show that the system is reliable and the results obtained compare favorably with those presented in other studies. The simple test procedure, including the preparation of ice specimens and the necessary measurements (failure load and geometrical configuration), makes it possible to obtain representative toughness values directly. The field instrument is surprisingly stiff, as indicated by the fracture-energy tests and recent tests on fresh-water ice where irregular crack-jumping was observed.

Included in the compliance calibration is also the compliance/stiffness of FIFT as $C=C_{\mathrm{FIFT}}+C_{\mathrm{SRCN}}$. It is of utmost importance to minimize the contribution from the loading device. As stated above, only a $1.5 \%$ difference was detected using FIFT instead of the test set-up used on Al specimens by Bubsey and others (1982) and Shannon and others (1982). Furthermore, in recent tests, a $40 \%$ increase in compliance was found when calibrating FIFT on a PMMA RTCLWL specimen compared with the compliance obtained using the stiff loading device of DeFranco and Dempsey (1991). This situation can be improved. Two instrument design details reduce the stiffness: the housing is not perfectly sealed and the most important fault is that the cushion expands, whereas it should be rigid, after the instability point has been reached. Another drawback with FIFT is the difficulty in controlling the loading rate.

The SRCN specimen does not generate high crack velocities when tested under displacement control. Due to the (sufficiently?) negative gsf, the loading geometry promotes stable crack growth. Since the righthand side of Equation (11) is always negative, any instability must be due to the ice properties, i.e. a consequence of negative $d R / d \dot{a}$ and a lack of stiffness in FIFT.

The test results obtained on the estimated crack velocity show a large variability. It must be noted that, while the tested-ice density, average grain-size and brine volume did differ slightly, the test temperature for series 1 was $-5^{\circ} \mathrm{C}$ while it was $-10^{\circ} \mathrm{C}$ for series 2 and 6 . Furthermore, the crack velocities presented are not measured but calculated using Equation (14) so, because of assumptions and approximations, these results must be regarded with caution. 
The fracture-toughness crack growth-rate dependency, i.e. greater toughness at slower crack-growth rates, found is very weak. In fact, Figure 9 shows virtually no trend at all. It is therefore likely that the "dependency" is a feature of the large variability of the sea-ice parameters involved. A consequence of such a rate-dependency of the toughness is that $d R / d \dot{a}<0$.

Is the observed crack growth stable? Many different concepts are evoked by the use of the word stable. Equation (16) gives the upper limit for the crack velocity when kinetic energy is not negligible. Equally, in the sense of imparted kinetic energy, the growth rate is stable and not dynamic in brackish sea ice. A further question is whether, provided that the crack grows under critical conditions, the observed growth rate is sub-critical (implying that it is creep growth) or is it just "stable" slow critical growth? Creep growth is accompanied by the emission of dislocations (blunting the crack) producing a largish creep zone ahead of the growing crack, while no stable growth means no dislocation emission and a small creep zone. A theoretical model by Hui and Riedel (1981), for a slowly growing crack in an elastic secondarycreeping material, shows that it is required that $n$ (the creep exponent) $>3$ for creep growth to occur. The Hui and Riedel model works well providing cracking is a result of secondary creep, which is not at all certain for ice. Applying $n=3.2$ and $B=5 \times 10^{-25}\left(\mathrm{~Pa}^{-3.2} \mathrm{~s}^{-1}\right)$ acquired from creep tests on ice from the Gulf of Bothnia and the Barents Sea to the Hui and Riedel model, a creep-zone size of the order of $10^{-13} \mathrm{~m}$ is obtained. The reader should immediately note that this is smaller than the inter-atomic distance of ice which makes this estimate very uncertain. So, at a first glance, this may seem inconsistent as "stable" growth is observed, and this should be accompanied by a largish creep zone". However, together with the observations made on the fracture surfaces, which gave evidence of brittle failure, this implies that critical crack growth in warm brackish sea ice does not necessarily have to be creep growth but may be slow and stable.

The agreement between this work and previous investigations on porosity effects is not so good. It must be noted that different loading rates, test temperatures and loading geometries were used and that the previous specimens are probably sub-sized, yielding fracture-toughness values that are too large. The work reported in this study shows a much more pronounced brine-volume dependence than that of Vaudrey (1977), Urabe and others (1980) and Timco and Frederking (1983) on columnar ice. However, a significant aspect of the analysis is that the tests were performed on warm granular ice where the crack-propagation direction was vertical downwards, i.e. parallel to the growth direction. These results can only

Recent creep tests, using SENB on fresh-water singlecrystal ice, by Wei and Dempsey (1991) showed a dislocation-free zone (DFZ) ahead of the crack tip. Adjacent to the DFZ and throughout the width of the specimen a plastic zone was detected. However, even though the specimens were stressed by a constant load for $5 \mathrm{~h}$, no crack growth was observed. therefore be applied to granular sea ice and not to columnar sea ice, since the ice types differ in their fundamental crystal texture. This would go a long way towards explaining the discrepancy in Figure 10b. It might even be possible that another micro-structural parameter that is related to brine volume affects the failure process in saline sea ice. This could be the subgrain-size, which is defined as the distance between the brine pockets. Urabe and Yositake (1981) investigated this matter and the results of DeFranco and others (1991) also point in this direction.

The results presented here support the use of $\sigma_{\mathrm{n}} / \sigma_{\mathrm{t}}<$ 0.4 as a specimen-size criterion. They are very interesting since they are virtually the same as those of Dempsey and others (1992), even though the tests were performed under different conditions. The loading geometries differed (SRCN vs SENB). The ice types and crack orientation differed (granular brackish sea ice vs freshwater S2 ice investigated for radial cracking). The temperatures differed $\left(-1.2^{\circ}\right.$ to $-10^{\circ} \mathrm{C}$ vs $\left.-10^{\circ} \mathrm{C}\right)$. The grain-sizes $(1.6-100 \mathrm{~mm}$ vs $3 \mathrm{~mm})$ and the loading rates differed.

\section{ACKNOWLEDGEMENTS}

The author gratefully acknowledges the helpful and stimulating discussions with Dr L. Fransson at Luleå University of Technology, Dr F. Ouchterlony at the Swedish Detonic Research Foundation, Dr B. Parsons at I.M.D., National Research Council Canada, Newfoundland and Dr S. DeFranco at Clarkson University, U.S.A. This research was supported by the Swedish National Industrial Board (SIND), Coldtech, the Swedish Council for Building Research (BFR), the Research Council of Norrbotten (Norrbottens Forskningsråd) and Skanska AB.

\section{REFERENCES}

American Society for Testing and Materials. 1983. Standard test method for plane strain fracture toughness of metallic materials. Philadelphia, PA, American Society for Testing and Materials E399-83.

Brown, S. D., R.B. Biddulph and P.D. Wilcox. 1964. A strengthporosity relation involving different pore geometry and orientation. 7. Am. Ceram. Soc., 47(7), 320-322.

Bubsey, R. T., D. Munz, W.S. Pierce and J. L. Shannon, Jr. 1982. Compliance calibration of the short rod chevron-notched specimen for fracture toughness testing on brittle materials. Int. F. Fract., 18(2), 125-133.

Cox, G. F. N. and W. F. Weeks. 1983. Equations for determining the gas and brine volumes in sea-ice samples. 7. Glaciol., 29(102), 306-316.

Currier, J.H. and E. M. Schulson. 1982. The tensile strength of ice as a function of grain-size. Acta Metall., 30(8), 1511-1514.

DeFranco, S.J. and J. P. Dempsey. 1990. Crack growth stability in S2 ice. In IAHR. The 10th Symposium on Ice, August 20-24, 1990, Espoo, Finland. Proceedings. Vol. 1. Espoo, Helsinki University of Technology, 168-181.

DeFranco, S.J. and J.P. Dempsey. 1991. Crack growth stability in saline ice. In Cocks, A. C. F. and A. R. S. Ponter, eds. Mechanics of creep brittle materials. Vol. 2. New York, Elsevier Applied Science, 2536.

DeFranco, S. J., Y. Wei and J. P. Dempsey. 1991. Notch acuity effects on the fracture toughness of saline ice. Ann. Glaciol., 15, 230-235.

Dempsey, J.P. 1991. The fracture toughness of ice. In Jones, S.J., R. F. McKenna, J. Tillotson and I. J. Jordaan, eds. Ice-Structure Interaction. IUTAM/IAHR Symposium, St. John's, Newfoundland, Canada, 1989. Berlin, Springer-Verlag, 109-145. 
Dempsey, J.P. and Y. Wei. 1988. Fracture toughness $K_{Q}$ and fractography of S1 type freshwater ice. In Salama, K., K. RaviChandar, D. M. R. Taplin and P. R. Rao, eds. Advances in Fracture Research. Vol. 5, Oxford, etc., Pergamon, 3421-3428.

Dempsey, J. P., Y. Wei and S. DeFranco. 1990. Notch acuity effects on the CTOD and $K_{Q}$ of ice. In Shah, S.P., S. E. Swartz and M.L. Wang, eds. Micromechanics of failure of quasi-brittle materials. New York, Elsevier Applied Science, 333-342.

Dempsey, J. P., Y. Wei and S.J. DeFranco. 1992. Notch sensitivity and brittleness in fracture testing of $\mathrm{S} 2$ columnar freshwater ice. Int. $\mathcal{F}$. Fract., 53, 101-120.

Fransson, L., L. Stehn, L. Ȧström and G. Danielsson. 1989a. Ice strength of level ice, part of the Bothnian testing program of the icebreaker Oden. Lulea, Luleå University of Technology. Division of Structural Engineering. (Project Report 63223-2.)

Fransson, L., L. Stehn, L. Ảström, B. Håkansson and A. Omstedt. 1989b. Variation of ice properties in an ice area of $1 \times 2 \mathrm{~km}$ in the Gulf of Bothnia, March 1988. In Axelsson, K. B. E. and L. Fransson, eds. POAC 89. The 10th International Conference on Port and Ocean Engineering under Arctic Conditions, June 12-16, 1989, Luled, Sweden. Proceedings. Vol. 3. Luleả, Tekniska Högskolan i Luleả, 1348-1357.

Fransson, L., T. Olofsson and J. Sandkvist. 1991. Observations of the failure process in ice blocks crushed by a flat indentor. In Muggeridge, D. B., D. B. Colbourne and H.M. Muggeridge, eds. POAC"91. The 11th International Conference on Port and Ocean Engineering under Arctic Conditions, September 24-28, 1991, St. John's, Canada. Procedings. Vol. 1. St. John's, Memorial University of Newfoundland. Ocean Engineering Research Centre, 501-514.

Goldstein, R. V. and N. M. Osipenko. 1991. Some questions on ice and ice cover fracture in compression. In Jones, S. J., R. F. McKenna, J. Tillotson and I. J. Jordaan, eds. Ice-Structure Interaction. IUT AM|IAHR Symposium, St. John's, Newfoundland, Canada, 1989. Berlin, SpringerVerlag, 251-266.

Gurney, C. and K.M. Ngan. 1971. Quasi static crack propagation in nonlinear structures. Proc. R. Soc. London, Ser. A, 325, 207-222.

Hillerborg, A., M. Modeer and P. E. Petersson. 1976. Analysis of crack formation and crack growth in concrete by means of fracture mechanics and finite elements. Cem. Concr. Res., 6, 773-782.

Hui, C.Y. and H. Riedel. 1981. The asymptotic stress and strain field near the tip of a growing crack under creep conditions. Int. F. Fract., 17(4), 409-425.

Ingraeffa, A. R. 1984. Three dimensional finite-element analysis of chevron-notched fracture specimens. In Underwood, J.H., S.W. Frieman and F. I. Baratta, eds. Chevron-notched specimens. Philadelphia, PA, American Society for Testing and Materials, 32-48. (Special Publication 855.)

International Society for Rock Mechanics. Commission on Testing Methods. 1988. Suggested methods for determining the fracture toughness of rock. Int. J. Rock Mech. Min. Sci. Geomech. Abstr., 25(2), 71-96.

Knudsen, F.P. 1959. Dependence of mechanical strength of brittle polycrystalline specimens on porosity and grain-size. F. Am. Ceram. Soc., 42(8), 376-387.

Kristic, V.D. and W.H. Ericson. 1987. A model for the porosity dependence of Young's modulus in brittle solids based on crack opening displacement. F. Mater. Sci., 22, 2881-2886.

Mai, Y.W. and A. G. Atkins. 1980. Crack stability in fracture toughness testing. F. Strain Anal., 15(2), 63-74.

Matsuki, K., S. Matsune and H. Takahasi. 1991. Boundary element analysis for standard specimen configuration in the ISRM suggested methods for determining fracture toughness for rock. Int. F. Rock Mech. Min. Sci. Geomech. Abstr., 28(5), 355-363.

Ouchterlony, F. 1982. Review of fracture toughness testing of rock. Solid Mechanics Archives, 17, 131-211.

Ouchterlony, F. 1985. Evaluation formulas for rock fracture toughness testing with standard core specimens. Stockholm, Swedish Detonic Research Foundation. (Report DS 1985:2.)

Ouchterlony, F. 1989a. Fracture toughness testing of rock with core based specimens; the development of an ISRM standard. In Mihasi, H., H. Takahasi and F.H. Wittmann, eds. Fracture toughness and fracture energy-test methods for concrete and rock. Rotterdam, Balkema, 231-249.

Ouchterlony, F. 1989b. On the background to the formulae and accuracy of rock fracture toughness measurements using ISRM standard core specimens. Int. F. Rock Mech. Min. Sci. Geomech. Abstr., 26(1), 13-23.
Parsons, B. L. 1990. Behavior of ice in the brittle range - a review. In Proceedings of the 43rd Canadian Geotechnical Conference, 10-12 October 1990, Québec. Vol. 1, 377-386.

Parsons, B. L., J. B. Snellen and B. Hill. 1986. Preliminary measurements of terminal crack velocity in ice. Cold Reg. Sci. Technol., 13(3), 233-238.

Parsons, B.L., J.B. Snellen and D.B. Muggeridge. 1988. The indentation and arrest stress intensity factors of first year columnar sea ice. In Saeki, H. and K. -i. Hirayama, eds. IAHR. Proceedings. The 9th International Symposium on Ice, 23-27 August 1988, Sapporo, Japan. Vol. 1. International Association for Hydraulic Research. Committee on Ice Problems, 502-511.

Parsons, B.L., J.B. Snellen and D. B. Muggeridge. 1989. The double torsion test applied to fine grained freshwater columnar ice and sea ice. In Cocks, A. C. F. and A. R. S. Ponter, eds. Mechanics of creep brittle materials. Vol. 1. New York, Elsevier Applied Science, 188-200.

Rice, R.W. 1977. Microstructure dependence of mechanical behavior. In MacCrone, R. K., ed. Properties and microstructure; treatise on materials science and technology. Vol. 11. New York, Academic Press, 20-369.

Rice, R.W., S. W. Freiman, R. C. Pohanka, J.J. Mecholsky and C. C. $\mathrm{Wu}$. 1978. Microstructural dependence of fracture mechanics parameters in ceramics. In Brandth, R. C., D. P. H. Hasselman and F.F. Lange, eds. Fracture mechanics of ceramics, crack growth and microstructure. Vol. 4. New York, Plenum Press, 849-876.

Shannon, J.L. and D.G. Munz. 1984. Specimen size and geometry effects on fracture toughness of aluminum oxide measured with shortrod and short-bar chevron-notched specimens. In Underwood, J. H., S. W. Frieman and F.I. Baratta, eds. Chevron-notched specimens. Philadelphia, PA, American Society for Testing and Materials, 270-280. (Special Publication 855.)

Shannon, J. L., Jr, R. T. Bubsey and W. S. Perce. 1982. Extended range stress intensity factor expressions for chevron-notched short bar and short rod fracture toughness specimens. Int. F. Fract., 19(3), R55-R58.

Sigl, L. S. 1991. On the stability of cracks in flexure specimens. Int. $\mathcal{F}$. Fract., 51, 241-254.

Stehn, L. 1990. Fracture toughness of sea ice. Development of a test system based on chevron notched specimens. (Licentiate thesis, Luleå University of Technology.)

Stehn, L. 1991. Fracture toughness of low salinity sea ice using short rod chevron notched specimens. In Muggeridge, D. B., D. B. Colbourne and H. M. Muggeridge, eds. POAC'91. The 11th International Conference on Port and Ocean Engineering under Arctic Conditions, September 24-28, 1991, St. John's, Canada. Proceedings. Vol. 1. St. John's, Memorial University of Newfoundland. Ocean Engineering Research Centre, 541-555.

Stehn, L. 1992. Fracturing and crack growth velocity of brackish sea ice. In IAHR. Proceedings. The 11th International Symposium on Ice, Banff. Vol. 2. International Association for Hydraulic Research, 1155-1166.

Stehn, L. and L. Fransson. 1989. A field instrument for fracture toughness testing on ice. In Axelsson, K. B. E. and L. Fransson, eds. $P O A C$ 89. The 10th International Conference on Port and Ocean Engineering under Arctic Conditions, June 12-16, 1989, Luled, Sweden. Proceedings. Vol. 1. Luleả, Tekniska Högskolan i Luleả, 300-310.

Timco, G.W. and R. M.W. Frederking. 1983. Flexural strength and fracture toughness of sea ice. Cold Reg. Sci. Technol., 8(1), 35-41.

Urabe, N. and A. Yoshitake. 1981. Strain rate dependent fracture toughness $\left(\mathrm{K}_{\mathrm{IC}}\right)$ of pure ice and sea ice. In International Association for Hydraulic Research. International Symposium on Ice, Québec, Canada, July 27-31, 1981. Proceedings. Vol. 2. Québec, Université Laval, 551-563.

Urabe, N., T. Iwasaki and A. Yoshitake. 1980. Fracture toughness of sea ice. Cold Reg. Sci. Technol., 3(1), 29-37.

Vaudrey, K. D. 1977. Ice engineering - study of related properties of floating sea-ice sheets and summary of elastic and viscoelastic analyses. Port Hueneme, CA, Civil Engineering Laboratory. (Technical Report R 860.)

Wei, Y. and J. P. Dempsey. 1991. Dislocation movement at crack tip of single crystals of ice. In Cooks, A. C. F. and A. R. S. Ponter, eds. Mechanics of creep brittle materials. 2. New York, Elsevier Applied Science, 62-74.

The accuracy of references in the text and in this list is the responsibility of the author, to whom queries should be addressed. 